\title{
PALIDOTOMI UNTUK PENYAKIT PARKINSON: LAPORAN 3 KASUS
}

\author{
PALLIDOTOMY FOR PARKINSON'S DISEASE: REPORT OF 3 CASES
}

Muhammad Agus Aulia, * Adolf Setiabudi, * Handrianto Setiajaya, *Agus Yunianto, * Lukman Ma'ruf*

\begin{abstract}
Pallidotomy for Parkinson's disease has recently developed in Indonesia for the last 6 years. Unlike Deep Brain Stimulation (DBS) implantation, Pallidotomy procedure is fully covered by Indonesian National Health Insurance, therefore it is expected that this procedure could be perform to all indicated Parkinson's Disease (PD) patients. The Indonesian Central Army Hospital is one of the few neurosurgery center that performed pallidotomy for PD patient in Indonesia, since 2017. This report evaluated the first 3 PD cases underwent pallidotomy in the hospital. The Unified Parkinson Disease Rating Scale (UPDRS)-motoric was used to evaluate the motor function pre-and post-pallidotomy. There were improvements of the UPDRS score post pallidotomy compared to baseline in On and Off condition. Pallidotomy can be part of management in PD patient with motor complication in spite of optimal medication.
\end{abstract}

Keywords: Pallidotomy, Parkinson's disease, Unified Parkinson's Disease Rating Scale (UPDRS)

\section{ABSTRAK}

Tindakan palidotomi untuk kasus Parkinson, merupakan prosedur yang baru dikembangkan di Indonesia sejak 6 tahun terakhir. Tidak seperti pemasangan deep brain stimulation (DBS), prosedur palidotomi ditanggung oleh jaminan kesehatan nasional Indonesia (BPJS), oleh karena itu diharapkan layanan ini dapat mencakup seluruh pasien Parkinson di Indonesia. Belum banyak pusat bedah saraf di Indonesia yang melakukan prosedur ini, antara lain RSPAD Gatot Soebroto, Jakarta sejak akhir tahun 2017. Tulisan ini mengevaluasi 3 kasus pertama pasien Parkinson yang dilakukan palidotomi di RSPAD Gatot Soebroto. Dengan menggunakan instrumen Unified Parkinson Disease Rating Scale (UPDRS)-motorik, dilakukan evaluasi pre- dan pascaoperasi. Terdapat perbaikan skor pascaoperasi baik saat off dan saat on dibandingkan dengan skor awal. Oleh karena itu palidotomi dapat menjadi pilihan terapi pada pasien Parkinson dengan komplikasi motorik meski sudah mendapat terapi medikasi yang optimal.

Kata kunci: Palidotomi, penyakit Parkinson, Unified Parkinson Disease Rating Scale (UPDRS)

*SMF Bedah Saraf Departemen Bedah RSPAD Gatot Soebroto, Jakarta. Korespondensi: aulia_oktar@yahoo.com.

\section{PENDAHULUAN}

Palidotomi, atau membuat lesi pada area posteroventral globus pallidus internus, merupakan bagian dari terapi untuk penyakit Parkinson. ${ }^{1-3}$ Tindakan ini telah dilakukan sejak tahun 1985 oleh Laitinen di Umea, Swedia. ${ }^{3}$ Pasien Parkinson yang memenuhi indikasi untuk dilakukan palidotomi mengalami perbaikan kualitas hidup berupa perbaikan gejala motorik (rigiditas, bradikinesia, dan tremor) dengan penurunan nilai skor Unified Parkinson Disease Rating Scale (UPDRS) yang signifikan dibanding skor awal. ${ }^{4-9}$ Beberapa studi jangka panjang menunjukkan perbaikan skor UPDRS pasca-dilakukan palidotomi dapat berlangsung hingga 4 tahun lebih. ${ }^{4,6}$

Meski palidotomi mulai ditinggalkan sejak perkembangan teknologi deep brain stimulation (DBS) untuk Parkinson, namun Movement Disorder
Society masih merekomendasikan palidotomi sebagai terapi yang efektif dan secara klinis berguna pada pasien Parkinson yang telah mendapat levodopa namun dengan komplikasi motorik (fluktuasi motorik dan diskinesia). ${ }^{1-3}$ Anderson dkk tidak mendapatkan perbedaan hasil luaran pasien Parkinson yang dilakukan DBS dan palidotomi. ${ }^{10}$

Di Indonesia, tindakan bedah saraf pada pasien Parkinson, baik itu implantasi DBS maupun brain lesioning (palidotomi-talamotomi) baru dimulai sejak tahun 2012. Namun penggunaan alat implan DBS untuk pasien Parkinson masih menjadi kendala karena biayanya sangat mahal dan belum ditanggung jaminan kesehatan pemerintah (BPJS). ${ }^{11}$ Sementara itu brain lesioning dapat menjadi pilihan untuk memperbaiki kualitas hidup pasien Parkinson dengan biaya yang terjangkau dan ditanggung oleh asuransi pemerintah (BPJS) karena tidak menggunakan alat implan. ${ }^{11}$ 
Tulisan ini merupakan laporan 3 kasus Parkinson pertama yang dilakukan tindakan palidotomi di RSPAD Gatot Soebroto, Jakarta, yang sejak akhir tahun 2017 sudah membuka pelayanan tindakan palidotomi untuk Parkinson dan gangguan gerak lainnya, yang dapat dipenuhi dengan jaminan kesehatan nasional Indonesia (BPJS). Dilakukan evaluasi motorik sebelum dan sesudah operasi dengan menggunakan skor UPDRS sub-motorik untuk menilai rigiditas, tremor dan diskinesia baik dalam fase on maupun off.

Instrumen Schwab and England Activities of Daily Living (ADL) Scale digunakan sebagai penilaian kualitas hidup pasien, bahwa pasien dalam kondisi vegetative (skor $0 \%$ ), dependen (skor 10\%$70 \%$ ), atau independen (skor 80\%-100\%). Bersama dengan Hoehn and Yahr Staging, instrumen ini sering digunakan untuk evaluasi pasien Parkinson, baik pada kasus awal maupun kasus lanjutan. ${ }^{12-13}$ Instrumen ini mempunyai korelasi dengan UPDRS dan memperlihatkan klasifikasi keparahan penyakit Parkinson yang pada instrumen UPDRS bagian activity of daily living (ADL) tidak secara eksplisit terlihat. ${ }^{12}$ Bjornestad dkk dalam studinya mengenai reliabilitas instrumen ini dalam menilai kehilangan dependensi pada pasien Parkinson, menemukan sensitivitas dan spesifitas Schwab and England ADL Scale sebesar $55 \%$ dan $92 \% .^{13}$

Fase on merupakan kondisi pasien pascaterapi medikamentosa yang meunjukkan respons motorik yang baik, berupa perbaikan rigiditas, bradikinesia, dan tremor. ${ }^{14}$ Adapun fase off adalah kondisi tidak adanya perbaikan respons motorik meski telah mendapat obat. ${ }^{14}$ Pasien dinyatakan mengalami perbaikan bila terdapat penurunan skor UPDRSmotorik pascaoperasi baik saat on maupun saat off..$^{14}$

\section{KASUS}

\section{Kasus 1}

Tn. B, 55 tahun, didiagnosis penyakit Parkinson sejak 12 tahun dengan gejala rigiditas pada kedua ekstremitas dan resting tremor terutama sisi kiri, serta hipokinesia. Pasien mendapat terapi levodopa dengan total dosis $300 \mathrm{mg}$ sehari, setelah berganti-ganti kombinasi obat levodopa dengan agonis dopamin dan penghambat catechol-O-methyltransferase (COMT-inhibitor), namun masih terdapat fluktuasi motorik. Dalam keadaan on pasien dapat melakukan aktivitas sehari-hari, namun dengan durasi fase on sebentar dan off yang lama (fluktuasi motorik). Tidak terdapat diskinesia, halusinasi, maupun efek samping obat yang lain. Skor UPDRS-motorik klinis pasien pre-operasi pada fase on 26, dan pada fase off 38 .

Dilakukan palidotomi unilateral sisi kiri pada pasien, kemudian dievaluasi klinis pascaoperasi dan 1 minggu setelahnya. Skor UPDRS-motorik 2 minggu pascaoperasi dalam keadaan on 16 dan dalam keadaan off 26. Adapun Skor Schwab and England ADL Scale sebelum dan sesudah operasi adalah $80 \%$.

\section{Kasus 2}

Ny. E, 48 tahun didiagnosis penyakit Parkinson sejak 8 tahun dengan gejala rigiditas terutama sisi kiri dan bradikinesia. Terdapat fluktuasi motorik, berupa masa on hanya sebentar dan lebih sering off. Pasien mendapat levodopa $300 \mathrm{mg}$ sehari dan triheksifenidil setelah beberapa kali kombinasi dengan agonis dopamin sebelumnya, namun terdapat fluktuasi motorik. Skor UPDRS-motorik sebelum operasi saat on adalah 7 dan pada saat off 25 .

Dilakukan palidotomi unilateral sisi kanan pada pasien. Didapatkan skor UPDRS-motorik 2 minggu pascaoperasi dalam keadaan on adalah 3 dan dalam keadaan off 20. Skor Schwab and England ADL Scale sebelum operasi adalah $80 \%$ yang menjadi $90 \%$ pascaoperasi.

\section{Kasus 3}

Ny. S, 72 tahun, mengalami penyakit Parkinson sejak 30 tahun dengan gejala rigiditas dominan seluruh extremitas. Pasien sudah berganti-ganti jenis levodopa, hingga menghentikan sendiri pengobatannya sejak 10 tahun terakhir karena timbul diskinesia dan fluktuasi motorik. Skor UPDRSmotorik awal dalam kondisi on adalah 60 dan kondisi off 73 .

Pasien dilakukan palidotomi unilateral sisi kiri. Didapatkan skor UPDRS motorik 2 minggu pascaoperasi saat on 52 dan saat off 73. Skor Schwab and England ADL Scale sebelum dan sesudah 
operasi tetap $30 \%$, namun tidak terdapat diskinesia pascaoperasi baik saat off maupun saat on pada sisi ipsilateral dan kontralateral.

\section{PEMBAHASAN}

Seluruh pasien adalah pasien yang sudah didiagnosis Parkinson sesuai kriteria klinis oleh dokter neurologi sebelumnya dan telah mendapat pengobatan levodopa yang optimal namun terdapat komplikasi motorik berupa fluktuasi motorik pada kasus pertama dan kedua, serta timbulnya diskinesia terkait L-dopa pada kasus ke-3.

Tindakan bedah untuk Parkinson baik implantasi DBS maupun palidotomi dan atau talamotomi diindikasikan untuk kasus penyakit Parkinson lanjut yang meski telah mendapat pengobatan optimal namun terdapat komplikasi motorik, berupa fluktuasi motorik dan terdapat diskinesia atau terdapat intoleransi terhadap efek samping obat anti parkinson. ${ }^{1-2,12}$ Beberapa kasus parkinsonisme sekunder, misalnya pascastroke, juga dapat dilakukan, namun luarannya tidak sebaik pada Parkinson primer. ${ }^{7,15}$

Kriteria lain ialah pasien dengan riwayat klinis responsif terhadap levodopa, fungsi kognisi yang baik, dan tidak ada komplikasi psikiatri. ${ }^{12}$ Tidak terdapat konsensus mengenai derajat keparahan penyakit parkinson yang menjadi batasan untuk dilakukan tindakan operasi. Keputusan tindakan bersifat individual disesuaikan dengan kondisi masing-masing pasien serta keluarga atau pengasuh. ${ }^{15}$

Ketiga pasien dalam laporan ini, pasien 1 dan 2 dengan masalah fluktuasi motorik dan pasien ketiga terdapat diskinesia, memiliki fungsi kognisi yang masih baik, respons terhadap levodopa, dan tidak terdapat masalah psikiatri. Oleh karena itu ketiga pasien ini memenuhi kriteria dan indikasi untuk dilakukan operasi palidotomi.

Palidotomi dilakukan menggunakan Frame Stereotactic $Z D$ dari Inomed. Seluruh pasien dilakukan MRI Kepala 3Tesla, kemudian ditentukan titik target di daerah posteroventral globus pallidus internus dengan piranti lunak Inomed Planning System. Lesi pada globus internus dibuat dengan mengunakan mesin generator radiofrekuensi Cosman, dengan suhu 70 derajat selama 60 detik melalui jarum elektroda Cosman dengan diameter tip 1,8mm dan panjang tip yang terbuka $2 \mathrm{~mm}$. Operasi dilakukan dalam keadaan sadar, dilakukan makrostimulasi sebelum membuat lesi permanen untuk menilai perbaikan motorik (rigiditas dan tremor) serta ada tidaknya komplikasi (kelumpuhan anggota gerak kontralateral, gangguan lapang pandang, dan disartria).

Pada kasus 1 dan 2, pasien masuk kriteria seleksi untuk menjalani palidotomi karena dengan pengobatan yang optimal masih terdapat fluktuasi motorik berupa saat on yang singkat serta off yang lama dan tidak terduga timbulnya sehingga mengganggu kualitas hidup pasien. ${ }^{15}$ Optimal secara implisit, menurut guideline National Institute for Health and Care Excellence (NICE) tentang pengobatan Parkinson bukan bergantung pada dosis atau lama pengobatan. Namun optimal berarti dengan dosis tertentu, dicapai respons motorik yang baik tanpa atau dengan efek samping obat yang minimal. "Optimal" bagi 1 pasien Parkinson belum tentu sama dengan "optimal" bagi pasien yang lain karena pengobatan bersifat individual, namun samasama mengalami fluktuasi motorik.

Pada pasien ini direncanakan palidotomi bertahap pada salah satu sisi yang lebih menganggangu aktivitas terlebih dahulu. Palidomi sisi kontralateral dapat dilakukan setelah 6 bulan dari operasi pertama untuk memperbaiki rigiditas pada ekstremitas sisi yang lain. Kombinasi palidomi sekaligus talamotomi kontralateral dapat dipertimbangkan untuk mengurangi tremor.

Pascaoperasi, pada pasien pertama terdapat perbaikan skor UPDRS-motorik saat on sebesar 38\% dan saat off sebesar 31\%. Perbaikan skor UPDRSmotorik terkait dengan perbaikan klinis rigiditas, bradikinesia, dan tremornya pada sisi kontralateral baik pada saat on maupun pada saat off. Demikian pula pada pasien ke-2, terdapat perbaikan skor UPDRS-motorik saat on, sebesar 57\% dan saat off sebesar 20\%. Hal ini sesuai dengan perbaikan luaran berdasarkan perbaikan skor UPDRS-motorik pascapalidotomi di beberapa pusat bedah saraf..$^{1-10}$ 
Palidotomi unilateral memperbaiki skor UPDRS-motorik 20-30\% pada keadaan off..$^{7}$ Vitek dkk, dalam studi selama 24 bulan terhadap 20 pasien Parkinson yang dilakukan palidotomi menunjukkan perbaikan skor UPDRS saat off sebesar $25 \% .{ }^{9}$ Eskandar dkk, dalam studi selama 24 bulan terhadap 68 pasien menunjukkan hasil yang tidak begitu berbeda, perbaikan skor UPDRS motorik $20 \%{ }^{8}$

Hingga tulisan ini dibuat, belum dilakukan upaya menurunkan dosis obat levodopa. Pascaoperasi, kedua pasien masih mendapat terapi levodopa dengan dosis yang sama seperti sebelum operasi. Laitinen dkk melaporkan reduksi dosis levodopa sebanyak 50 hingga $70 \%$. Meski beberapa literatur lain menunjukkan tidak ada perubahan dosis levodopa yang signifikan pascapalidotomi. Adanya penurunan skor UPDRS-motorik, menunjukkan perbaikan klinis gejala motorik dan fluktuasi motorik, yang berarti dapat memperbaiki kualitas hidup pasien.

Pada pasien ke-3, pasien sudah menderita penyakit Parkinson sejak 30 tahun, dan menghentikan sendiri pengobatan levodopanya disebabkan efek diskinesia yang menganggu hingga menyebabkan kondisi off sepanjang waktu dan membutuhkan bantuan untuk kegiatan sehari-hari. Meski usia 72 tahun, namun fungsi kognitif pasien masih baik, tidak terdapat demensia. Fungsi kognitif yang masih baik dan terdapat diskinesia yang berat menjadi kriteria inklusi pasien untuk dilakukan palidotomi bertahap. ${ }^{12}$ Pada pasien ini dilakukan palidotomi unilateral, sisi kiri terlebih dahulu, karena melakukan palidotomi bilateral pada satu tahap dapat meningkatkan risiko terjadinya komplikasi seperti disartria, disfagia, hipofonia maupun gangguan kognitif. ${ }^{8}$

Pasien kembali mendapat terapi L-Dopa dan terdapat sedikit perbaikan dari skor UPDRS-motorik pasien pascaoperasi saat on sebesar 13\%, namun tidak ada perbaikan saat off dan tidak ada perbaikan skor Schwab dan England ADL Scale. Hal ini disebabkan karena kondisi awal yang sudah berat dan perbaikan rigiditas hanya terjadi pada satu sisi yang dioperasi saja. Namun pada evaluasi klinis diskinesia saat on dan off, dari segi durasi dan disabilitas, terdapat perbaikan yang signifikan bahkan pada kedua sisi (ipsilateral dan kontralateral).
Lang dkk, juga melaporkan perbaikan diskinesia pada sisi ipsilateral pascapalidotomi unilateral, namun efek pada sisi ipsilateralnya berkurang setelah 1 tahun. $^{6}$ Laporan lain juga menunjukkan perbaikan diskinesia pada kedua sisi, namun efek pada sisi ipsilateralnya berkurang setelah 6 bulan. Dalvi dkk melaporkan perbaikan diskinesia baik pada sisi ipsilateral maupun kontralateral yang signifikan hingga 1 tahun pascapalidotomi. ${ }^{5,7-8}$

Tidak terdapat komplikasi maupun efek samping dari tindakan palidotomi unilateral terhadap ketiga pasien ini. Beberapa literatur melaporkan komplikasi yang dapat terjadi pascapalidotomi seperti disartria, disfagia, hipofonia, kelemahan motorik kontralateral dan gangguan lapang pandang ${ }^{4-10}$ sebesar $19-26 \% .^{7}$ Risiko menjadi lebih besar pada pasien yang dilakukan tindakan palidotomi bilateral (kedua sisi) secara langsung (satu tahap). Favre dkk merekomendasikan palidotomi bilateral dikerjakan secara bertahap dengan interval selama lebih dari 6 bulan setelah operasi pertama. ${ }^{16}$

Sejalan dengan progresivitas penyakit Parkinson, pasien akan mengalami penurunan fungsi motorik maupun nonmotorik. Pada pasien yang dilakukan palidotomi, diharapkan perbaikan motrik dapat tetap bertahan hingga 5 tahun pascaoperasi. ${ }^{6}$ Fazzini dkk, menunjukkan perbaikan skor UPDRSmotorik saat off yang bertahan hingga 4 tahun pascapalidotomi. ${ }^{17}$

Diperlukan evaluasi UPDRS-motorik berkala pascapalidotomi. Jika terdapat penurunan skor UPDRS-motorik, selain evaluasi klinis, juga dilakukan evaluasi MRI kepala untuk menilai letak lesi serta besar lesi palidotomi di globus palidus internus. Pertimbangan untuk melakukan repalidotomi pada sisi yang sama adalah bila letak lesi tidak pada daerah posteroventral palidotomi ataupun ukuran lesi yang kecil. ${ }^{7}$ Meski literatur menunjukkan perbaikan skor UPDRS motorik yang dapat bertahan lama, dalam studi kasus ini diperlukan followup jangka panjang serta jumah sampel yang lebih banyak untuk menilai efektivitas palidotomi dalam memperbaiki skor UPDRS-motorik, diskinesia serta evaluasi efek samping dan komplikasi. 


\section{KESIMPULAN}

Palidotomi dapat menjadi pilihan terapi pada pasien Parkinson yang meskipun sudah mendapat terapi anti-Parkinson yang optimal namun terdapat fluktuasi motorik dan diskinesia. Palidotomi dapat memperbaiki skor UPDRS-motorik pada pasien Parkinson dengan perbaikan pada rigiditas, bradikinesia, dan diskinesia.

\section{DAFTAR PUSTAKA}

1. Goetz CG, Poewe W, Rascol O, Sampaio C. Evidencebase medical review update: Pharmocological and surgical treatment of Parkinson's disease: 2001 to 2004. Mov Disorder. 2005;20:523-39.

2. Fox SH, Katzenschlager R, Lim SY, Ravina B, Seppi $\mathrm{K}$, Coelho M, dkk. The movement disorder society evidence-based medicine review update: treatments for the motor symptomps of Parkinson disease. Mov Disorder. 2011;26:S2-41.

3. Cif L, Hariz M. Seventy years with the globus pallidus: pallidal surgery for movement disorders between 1947 and 2017. Mov Disorder. 2017;00:1-11.

4. Aguiar PMC, Ferraz HB, Ferraz FP, Saba RA, Hisatugo MK, Andrade LAF. Motor performance after poserovental pallidotomy and VIM thalamotomy in Parkinson disease. Arq Neuropsiquitr. 2000;58(3B):830-5.

5. Baron MS, Vitek JL, Bakay RAE, Green J, Kancoke Y, Hasimoto T, dkk. Treatment of advanced Parkinson's disease by internal globus pallidotomy: 1-year results of a pilot study. Ann Neurol. 1996;40:355-66.

6. Fine J, Duff J, Chen R, Hutchison W, Lozano AM, Lang AE. Long-term follow up of unilateral pallidotomy in advanced Parkinson's disease. N Engl J Med. 2000;342:1708-13.

7. Hariz MI. Pallidotomy for Parkinson's disease. Dalam: Lozano AM, Gildenberg PL, Tasker RR, editor. Textbook of stereotactic and functional neurosurgery. Edisi ke-2. Berlin/Heidelberg: Springer-Verlag. 2009. h. 1540-7.

8. Eskandar EN, Shinobu LA, Penney JB Jr, Cosgrove GR, Counihan TJ. Stereotactic pallidotomy performed without using microeletrode guidance in patients with
Parkinson's disease: surgical technique and 2-year results. J Neururg. 2000;92:375-83.

9. Vitek Jl, Bakay RA, Freeman A, Evatt M, Green J, McDonald W, dll. Randomized trial of Pallidotomy versus medical therapy for Parkinson's disease. Ann Neurol. 2003;53:558-69.

10. Anderson WS, Clatterbuck RE, Kobayashi K, Kim JH, Lenz FA. Lesions versus Implanted Stimulators in Functional Neurosurgery. Dalam: Lozano AM, Gildenberg PL, Tasker RR, editor. Textbook of stereotactic and functional neurosurgery. Edisi ke-2. Berlin/Heidelberg: Springer-Verlag. 2009. h. 1350-7.

11. DEPKES RI. Peraturan Menteri Kesehatan Republik Indonesia No. 52 tahun 2016 tentang standar tarif pelayanan kesehatan dalam penyelenggaraan program jaminan kesehatan. 2016

12. Goetz CG, Poewe W, Rascol O, Sampaio C, Stebbins GT. The unified Parkinson's disease rating scale (UPDRS): status and recommendations. Mov Disorder. 2003:18:738-50.

13. Bjornestad A, Tysnes OB, Larsen JP, Alves G. Reliability of three disability scales for detection of independence loss in Parkinson's disease. Parkinsons Dis. 2016;2016:1941034.

14. Goetz CG, Tilley BC, Shaftman SR, Stebbins GT, Fahn S, Martin PM, dkk. Movement disorder societysponsored revision of the unified Parkinson's disease rating scale (MDS-UPDRS): scale presentation and clinimetric testing results. Mov Disorder. 2008:23:2129-70.

15. Tan EK, Jankovic J. Patient Selection for surgery for Parkinson's disease. Dalam: Lozano AM, Gildenberg PL, Tasker RR, editor. Textbook of stereotactic and functional neurosurgery. Edisi ke-2. Berlin/ Heidelberg: Springer-Verlag. 2009. h. 1530-8.

16. Favre J, Burchiel KJ, Taha JM, Hammerstad J. Outcome of unilateral and bilateral pallidotomy for Parkinson's disease: patient assessment. Neurosurgery. 2000;46(2):344-53.

17. Fazzini E, Dogali M, Stereo D, Eidelberg D, Beric A. Stereotactic pallidotomy in the treatment of Parkinson's disease: a long term follow-up of unilateral pallidotomy. Neurology 1997;48:1273-7. 